\title{
Acquisition and extinction with rewarded goal box placements interpolated among training trials
}

\author{
ALVIN J. NORTH ${ }^{2}$ and DIANA FOSTER CARL, Southern \\ Methodist University, Dallas, Texas
}

In a factorial design, rats were given 15, 30, or 60 training trials in a runway with 0,15 , or 30 rewarded goal placements interpolated among runs. Then 6.3 extinction trials were given. Terminal acquisition goal speeds increased with number of placements and also number of rewards $\left(N_{\mathrm{g}}\right)$. Resistance to extinction was found to vary inversely with number of placements, inversely with $N_{g}$, and independently of amount of training with $N_{g}$ being controlled.

Using a runway, Theios \& Brelsford (1964) compared the extinction performance of groups of rats previously given 50 pretraining rewarded goal box placements and 10 rewarded runs (Group 10-60), no placements and 60 runs (Group 60-60), and no placements and 10 runs (Group 10-10). They found that Group 10-60 extinguished faster than Group 60-60, which in turn extinguished faster than Group 10-10. They concluded that "resistance to extinction is (a) an increasing function of the number of times the animal performs the response and (b) a decreasing function of the number of rewards experienced at the goal [p. 466]."

The present study was generally similar to that of Theios \& Brelsford (1964), except that placements were interpolated among training trials instead of being given prior to training. The experimental variables in a factorial design were number of training trials and number of placements interpolated among training trials. The main questions were as follows: (a) Would interpolating placements among training trials result in increased levels of acquisition of the running response? (b) Would resistance to extinction vary inversely with number of interpolated placements? (c) With number of rewarded goal experiences $\left(\mathrm{N}_{\mathrm{g}}\right)$ held constant, what relationship would there be between resistance to extinction and amount of training?

\section{METHOD}

The Ss were 54 male albino rats of the Holtzman strain, 90 to 110 days old when the study began. They were housed in individual cages in an air-conditioned and continuously illuminated room.

The apparatus was a $4 \times 4 \times 58$ in. straight runway having a 10-in. white start box, a 32-in. black runway section, and a 16-in. black goal box. The three sections were separated by manually-operated retrace doors and had hinged lids covered by hardware cloth. Four photoelectric relays and four $1 / 100 \mathrm{sec}$ timers measured time to traverse runway segments. Clock 1 (start time) was activated by raising the start slide and measured time to cover the first 8 in. beyond the start slide. Clocks 2 and 3 (running times) measured time to traverse the next 6 and 26 in., respectively. Clock 4 (goal time) measured the time to cover the last $6 \mathrm{in}$. of the goal box (GB) to a light beam located 2 in. from the reward receptacle (a 1/2-tsp measuring spoon attached to the goal box end).

After habituation to the laboratory with food and water being continuously available, all Ss were placed on food deprivation. They were fed $12-14 \mathrm{~g}$ of Purina Lab Chow $30 \mathrm{~min}$ after the end of the daily experimental sessions. Because the duration of acquisition training varied, the various treatment groups began pretraining and acquisition phases at different times so that they could begin the extinction phase with the same deprivational history. Pretraining consisted of seven days of handling, reward experiences in a neutral gray box and nonrewarded trials (seven in all) in the runway.

The experimental variables in a factorial design were (a) number of acquisition training trials $(15,30$, or 60 rewarded runs) and (b) number of rewarded goal box placements $(0,15$, or 30) which were interpolated among the training trials. The $54 \mathrm{Ss}$ were assigned at random to the resulting nine treatment groups of six Ss each. The nine groups were designated as P0T 15, P0T30, P0T60, P15T15, P15T30, P15T60, P30T 15, $P 30 T 30$, and P30T60 where the digits after $P$ and $T$ indicate the number of placements and training (rewarded runs) trials, respectively. For example, Group P30T 15 had 30 placement and 15 training trials. The design provided that planned comparisons could be made among certain groups matched for number of reward experiences $\left(\mathrm{N}_{\mathrm{g}}\right)$ and differing in the number $(N)$ of training trials.

During both acquisition and extinction phases, each rat was given three running and/or placement trials per day with at least a $20 \mathrm{~min}$ intertrial interval. Placements were randomly interpolated among running trials with the restriction that no more than three placements could occur in sequence. On a placement trial $S$ was placed in the $G B$ with his head facing and 1 in. from the reward. On both running and placement trials, $\mathrm{S}$ was removed from the GB after taking the reward (two $97 \mathrm{mg}$ Noyes tablets) in his mouth. S was kept in his home cage between trials.

Extinction consisted of 63 nonrewarded running trials at three per day. $S$ was kept in the goal box for 20 sec. If $S$ did not reach the goal within $2 \mathrm{~min}$, he was removed from the runway.

\section{RESULTS}

All time scores were transformed to reciprocals and multiplied by 100 . Then for each $S$ the median of these scores was determined for each block of five acquisition running trials and for each block of nine extinction trials. In order to simplify this report, findings for Clock 2 will be omitted. The transformed scores for Clocks 1, 3, and 4 are called "start," "run," and "goal" speeds, respectively, and the medians of these were the values used in all analyses of variance.

Table 1 shows the means of median start, run, and goal speeds in the last five-trial block of acquisition (terminal acquisition or TA). Two-way analyses of variance were done on each of these measures. The Fs for Placements on the start, run, and goal measures were $F=1.52,0.09$, and 3.00, respectively, $\mathrm{df}=2 / 45$. The marginally significant $F(p<.10)$ for goal speeds suggests that interpolated placements may increase goal speeds. The corresponding Fs for Training were $1.85,4.45$, and 3.93 ( $p<.05$ for the latter two). Although the start and run means consistently increased with amount of training, those for goal speeds did not increase monotonically. The Fs for Placements by Training were nonsignificant.

Planned comparisons were made of the TA means of pooled groups having 30,45 , or 60 rewards (via either placements or

Table 1

Means of Median Start, Run and Goal Speeds in the Last Five Acquisition Running Trials

\begin{tabular}{llrr}
\hline Group & Start & Run & Goal \\
\hline POT15 & 182.3 & 161.8 & 342.8 \\
POT30 & 192.8 & 182.3 & 364.7 \\
POT60 & 211.7 & 190.7 & 442.8 \\
P15T15 & 196.5 & 167.3 & 329.3 \\
P15T30 & 210.2 & 183.7 & 417.5 \\
P15T60 & 233.7 & 191.3 & 361.3 \\
P30T15 & 176.2 & 161.7 & 394.7 \\
P30T30 & 180.2 & 182.3 & 457.2 \\
P30T60 & 200.7 & 187.0 & 431.2 \\
\hline
\end{tabular}




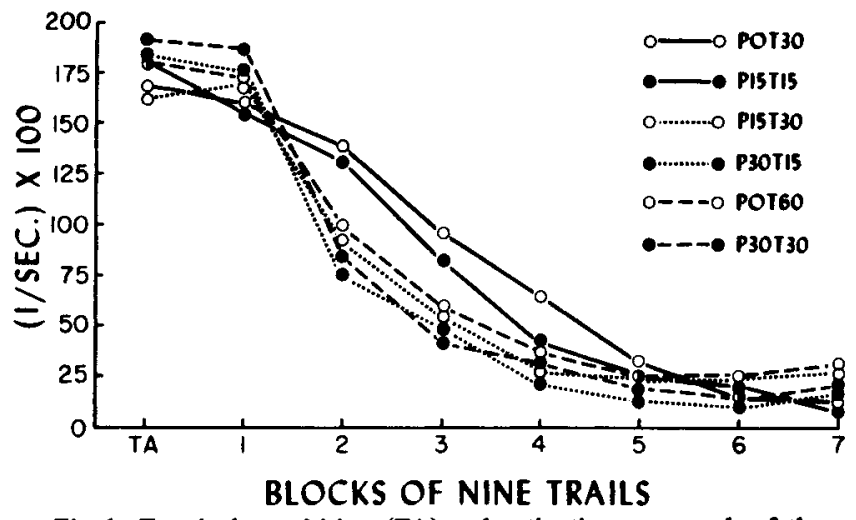

Fig. 1. Terminal acquisition (TA) and extinction run speeds of three pairs of groups matched for $\mathbf{N}_{\mathrm{g}}$ but differing in $\mathbf{N}$ within each pair. Each data point is the mean of six $S$ medians.

runs). Each of these three groups $(\mathrm{N}=12)$ was composed of two groups matched for $\mathrm{N}_{\mathrm{g}}$, but differing with respect to $\mathrm{N}$ (P0T30 vs P15T15; P15T30 vs P30T15; and P0T60 vs $P$ 30T30). A significant $F$ was obtained only for the goal speed measure $(F=5.41, d f=2 / 45, p<.01)$. The goal speed means for the groups having 30,45, and 60 rewards were 346.5, 406.1 , and 450.0 , respectively. Subsequent $t$ tests showed that the latter two means differed significantly from the first, but not from each other. None of the $t$ tests comparing the TA means of groups matched for $\mathrm{N}_{\mathrm{g}}$, but differing in $\mathrm{N}$ was significant. Each of these latter tests, of course, had fairly low power.

Turning to the extinction data, trend analyses of variance showed a significant Stages (of extinction) effect for start, run, and goal measures $(F=65.40,22.46$, and 145.83 , respectively, $\mathrm{df}=6 / 270, \mathrm{p}<.01)$. These findings merely demonstrate the decremental effect of successive nonreward. The corresponding Fs for Placements, Training, and Training by Stages were nonsignificant. On the other hand, there were significant Fs for the Placement by Stages interaction for both run and goal measures $(F=2.58$ and 3.33 , respectively, $\mathrm{df}=12 / 270$, $\mathrm{p}<.01$ ). There were also significant Placement by Training by Stages interactions on run and goal measures $(F=1.88$ and 2.10 , respectively, $\mathrm{df}=24 / 270, \mathrm{p}<.01$ ). Plots of run and goal speed curves generally showed that Ss with 30 placements extinguished faster than did those having 0 or 15 placements. The differences among these curves, however, varied complexly with the level of training.

As previously planned, a special analysis was made of the data of the three pairs of groups matched for $\mathrm{N}_{\mathrm{g}}$, but differing within each pair with respect to $N$. Figures 1 and 2 show the extinction run and goal speed curves for each of the six groups under consideration (start speed curves were irregular and unrevealing). In general within-pair differences were small, but

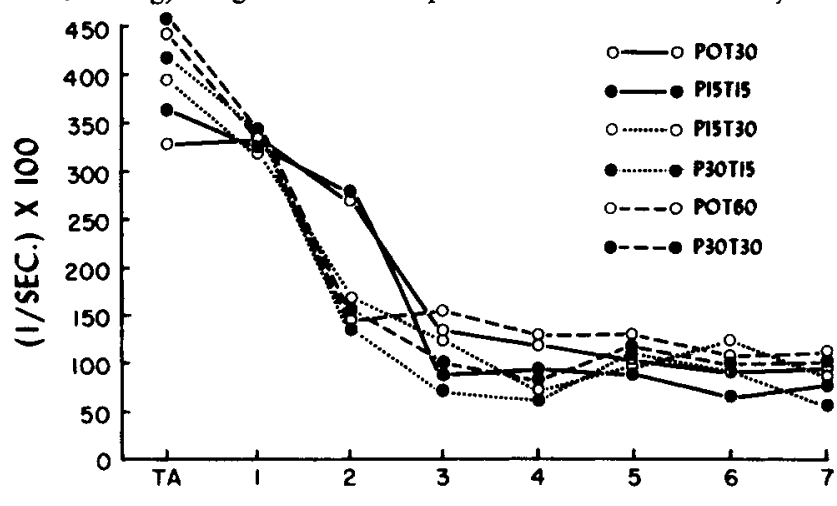

BLOCKS OF NINE TRIALS

Fig. 2. Terminal acquisition (TA) and extinction goal speeds of three pairs of groups matched for $\mathbf{N}_{\mathrm{g}}$ but differing in $\mathbf{N}$ within each pair. Each data point is the mean of six $S$ medians. between-pair differences (specifically, the pair P0T30 and P15T15 vs the two other pairs) were marked.

In order to test whether resistance to extinction depends on $\mathbf{N}$ when $\mathrm{N}_{\mathrm{g}}$ is held constant, the $\mathrm{F}$ for Groups by Stages was determined for each of the three pairs of groups on run and goal measures. None of the resulting six Fs approached significance.

In order to test whether resistance to extinction depends on $\mathrm{N}_{\mathrm{g}}$, the data of each pair of groups were pooled, resulting in three groups having $\mathrm{N}_{\mathrm{g}}$ equal to 30,45 , and 60 . Significant Fs for the Groups by Stages interaction were obtained in the case of both run and goal measures $(F=4.73$ and 4.83 , respectively, $\mathrm{df}=12 / 270, p<.01)$. Subsequent tests of the simple effects of the $\mathrm{N}_{\mathrm{g}}$ factor at the several stages of extinction yielded Fs of 11.44 and 11.27 for run and goal measures, respectively, on Trial Block $2(\mathrm{df}=2 / 315, \mathrm{p}<.01)$. The figures indicate that the pooled group having 30 rewards showed more initial resistance to extinction than did the pooled groups having 45 or 60 rewards.

\section{DISCUSSION}

The marginally significant $F$ for Placements in the case of acquisition goal speeds suggests that interpolating rewarded goal placements among training trials increases speed of approach. Such a finding would lend support to Spence's (1956) theory that $\mathrm{N}_{\mathrm{g}}$ affects $\mathrm{K}$, which in turn affects $E$ (reaction potential). Further support for Spence's notion derives from the finding that pooled groups having 45 or 60 rewards (via runs or placements) had significantly faster goal speeds than did Ss having 30 rewards. The lack of any significant differences in acquisition within paired groups matched for $\mathrm{N}_{\mathrm{g}}$, but differing in regard to $\mathrm{N}$, suggests that $\mathrm{H}$ may fairly quickly become asymptotic in runway training. If so, then in the present experiment group differences in acquisition speeds would be attributable mainly to differences in $\mathrm{K}$ instead of $\mathrm{H}$.

The significant Placement by Stages interactions for extinction run and goal speeds suggest that interpolating rewarded goal placements during training decreases resistance to extinction. The Es were unable to find any interpretable pattern in the significant triple interactions of these factors with Training.

The significant Groups by Stages interactions during extinction in the case of the pooled groups having had 30,45 , or 60 rewards suggest that resistance to extinction varies inversely as the number of rewards. Since an increase in the number of rewards, whether by placements or runs, theoretically increases the magnitude of fractional anticipatory reward $\left(r_{R}\right)$, which in turn is associated with greater frustration of nonreinforcement $\left(\mathrm{r}_{\mathrm{F}}\right)$, the foregoing findings are generally consistent with the frustration theory of reinforcement (Amsel, 1958).

The lack of any significant differences during extinction between groups matched for $\mathrm{N}_{\mathrm{g}}$, but differing in regard to $\mathrm{N}$, suggests that resistance to extinction does not vary with amount of training when $\mathrm{N}_{\mathrm{g}}$, is controlled, provided that $\mathrm{Ss}$ have exceeded some minimum number of trials. In the present comparisons, all groups had at least 15 training trials, which, as suggested earlier, may have resulted in nearly asymptotic values of $H$. Perhaps Theios \& Breslford's (1964) Group 10-60, which extinguished more rapidly than their Group $60-60$, was further from asymptotic $H$ than were the groups in our comparisons. If so, then the findings in the two experiments are not really discrepant.

REFERENCES

AMSEL, A. The role of frustrative nonreward in noncontinuous reward situations. Psychological Bulletin, 1958, 55, 102-119.

SPENCE, K. W. Behavior theory and conditioning. New Haven: Yale University Press, 1956.

THEIOS, J., \& BRELSFORD, J. Overlearningextinction effect as an incentive phenomenon. Journal of Experimental Psychology, 1964, 67, 463-467.

NOTES

1. Supported in part by National Science Foundation Grant GB-2873. 2. Now at the Univ. of Texas Southwestern Medical School at Dallas. 